\title{
CONGENITAL PSEUDARTHROSIS OF THE CLAVICLE
}

\author{
Robert OWen, Oswestry, ENGLAND \\ From the Robert Jones and Agnes Hunt Orthopaedic Hospital, Oswestry
}

Defect in the shaft of one clavicle in early life is a clinical curiosity of some rarity and presents numerous points of interest.

The lesion presents as a swelling invariably situated in the mid-clavicle, usually noticed at birth or occasionally in infancy and early childhood. The shoulder shown in Figure 1 exemplifies the typical features of the condition. The pseudarthrosis increases in size over a period of years, giving rise to a progressive deformity which assumes a lanceolate form, often encroaching on the skin and frequently necessitating surgical treatment. There is usually no systemic blemish, but there may be an alteration in the shape of the shoulder girdle, with asymmetry of the upper part of the trunk. The radiographs show characteristic changes. The medial half of the clavicle is large and protrudes forwards and upwards, whereas the lateral half is situated below, pointing upwards and backwards and ending in a bulbous mass at the pseudarthrosis (Fig. 2).

The material presented here is derived from thirty-three patients. Four of these were personal cases treated by tibial bone grafting. The other twenty-nine were collected from one American and twenty-five British orthopaedic colleagues. Seventy surgeons altogether were approached; so it is fair to assume that a single clinician may encounter at most two or three cases in a lifetime.

The literature on this topic has accumulated in recent years but most reports describe isolated cases. Fitzwilliams (1910) was probably the first to describe the condition in the English literature, and Saint-Pierre reported one case in 1930. Continental reports, especially

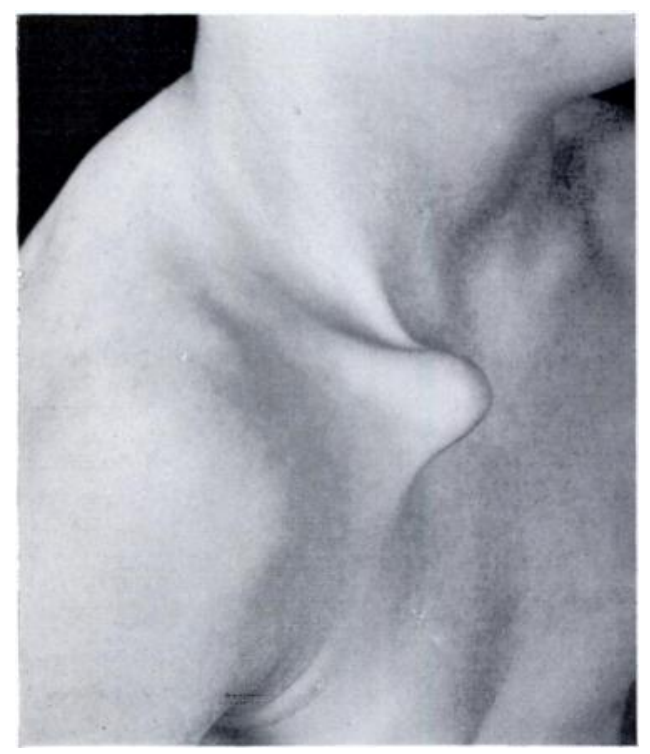

FIG. 1

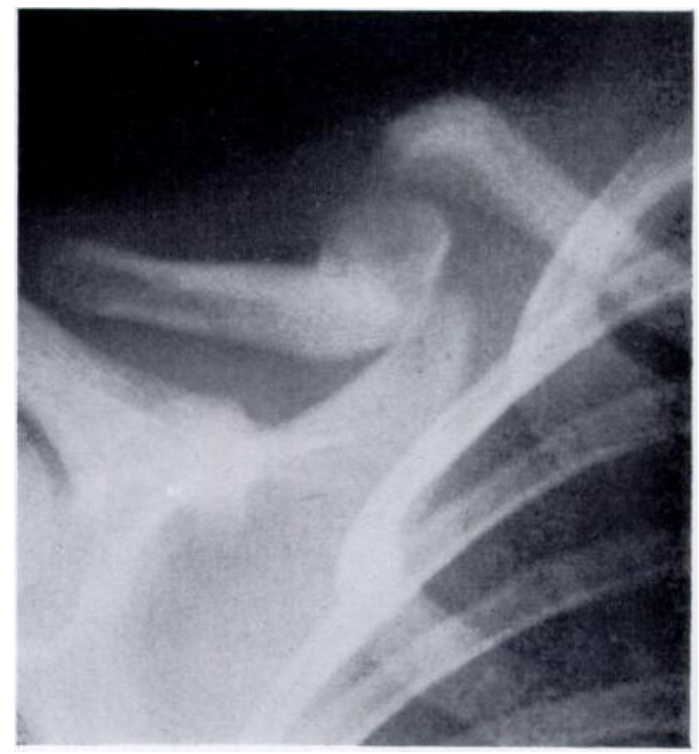

Fig. 2

Figure 1-The presenting lesion of the right clavicle in a boy of 7 years. Figure 2-Radiograph showing the relative position of the two clavicular segments. 
from Italy, France and Scandinavia, have usually appeared in radiological journals (Foco 1946, Støren 1946, Cesarani 1947, Pessagno 1954). Henderson (1923) and Moore (1949) contributed to the American literature. In 1960 Carpenter and Garrett described a boy of five years with a classical lesion. In 1961 Sakellarides described twenty cases with clavicular defects of all types, of which four could be regarded as being of congenital origin. Little was written on the subject in Britain until Alldred (1963) presented nine cases collected from London and New Zealand. In the main our findings and conclusions coincide, except for some details to be discussed later.

\section{HISTORY AND CLINICAL FEATURES}

The condition is usually noticed by the mother when feeding the baby or later by parent or doctor after a minor injury, when a lump is found. The obstetric history is not always available, but no serious complication of pregnancy was reported in this series and in no case

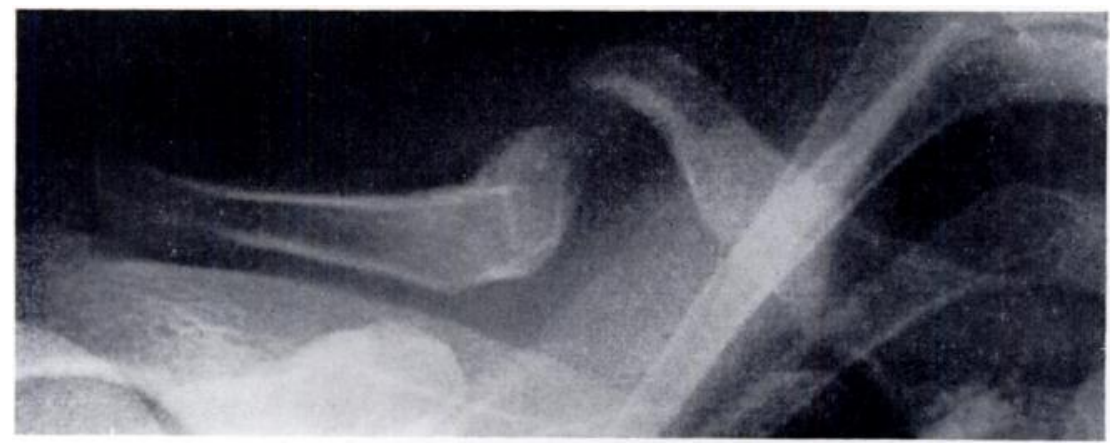

Fig. 3

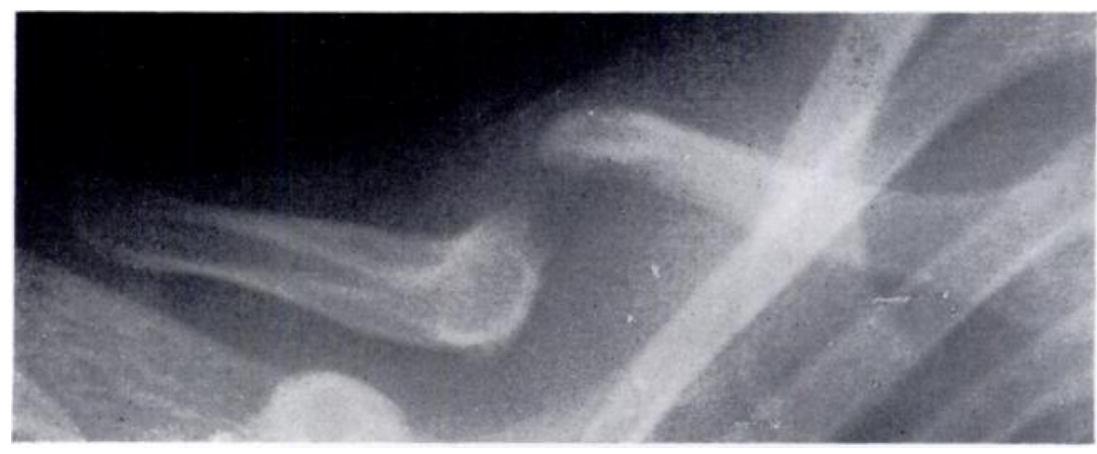

Fig. 4

Identical lesions of the right clavicle in father and daughter.

was delivery unduly difficult, although forceps were used in at least three instances. Precipitant delivery occurred in one case. Unfortunately this aspect of the history is not reliable enough to permit any conclusions about etiology. There was no family history of more widespread deformities or of neurofibromatosis, but included in the series were a father and daughter with identical lesions in the right clavicle (Figs. 3 and 4). Associated deformities were not significant. One child had a funnel chest, there were four with prominent cervical ribs, one with spina bifida occulta of the cervical spine and two girls with somewhat prominent foreheads. There were no café-au-lait stigmata, although one of my own cases and two others had freckles.

Symptoms were relatively few. In most cases, however, the protrusion was progressive, resulting in difficulties with dress and embarrassment in the older girls. In four of the patients 
the overlying skin became thin and atrophic. When critically examined many were found to have drooping of the shoulder with asymmetry, and prominence of the vertebral border of the scapula with exaggeration of the clavicular lump on shrugging the shoulders. Aching around the shoulder girdle after exercise and referred discomfort in the upper arm was present in eleven of the patients. No vascular symptoms were reported. A few complained of clicking and some weakness of the arm with limitation of abduction. Disability, however, was never serious and the main reason for seeking advice was because of increasing swelling.

TABLE I

Clinical Features

\begin{tabular}{|c|c|c|c|}
\hline Sex & \multicolumn{2}{|c|}{23 female } & 10 male \\
\hline Age diagnosed & $\begin{array}{l}\text { Birth to } 2 \text { weeks } \\
15\end{array}$ & $\begin{array}{c}2 \text { weeks to } 2 \text { years } \\
10\end{array}$ & After 2 years \\
\hline Site & \multicolumn{3}{|c|}{ All right sided } \\
\hline Operation & \multicolumn{3}{|c|}{20 patients } \\
\hline Type . & \multicolumn{2}{|c|}{ Bone graft 16} & Excision 4 \\
\hline Findings & True joint 14 & No record 3 & Fibrous bridge 3 \\
\hline
\end{tabular}

TABLE II

Results OF Operation

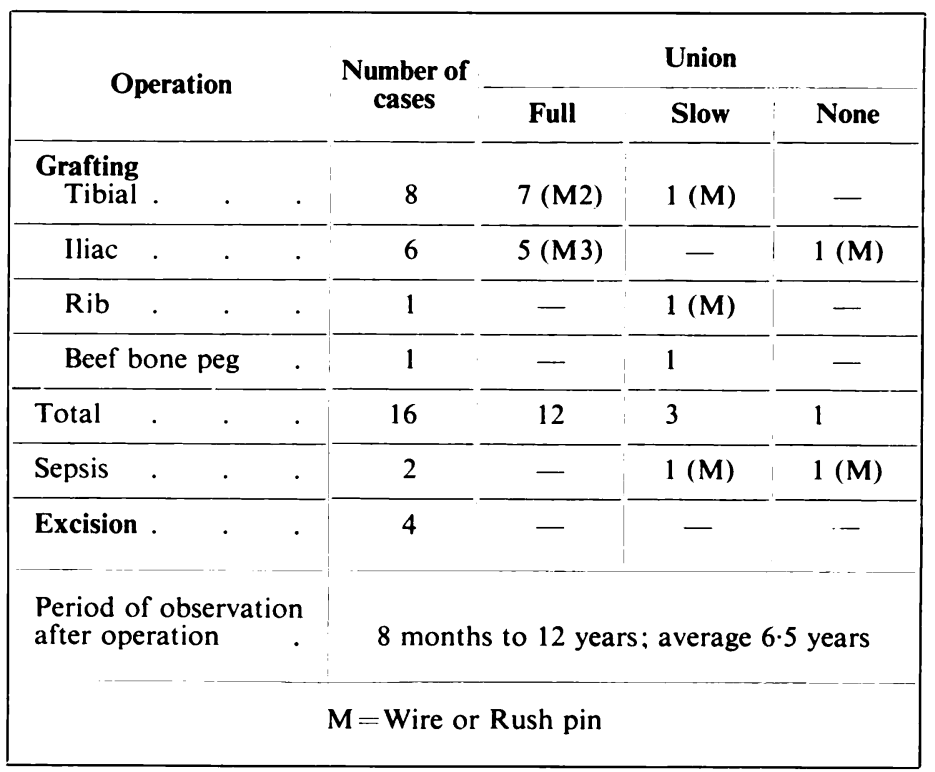

Differential diagnosis-The clavicular defect in craniocleidodysostosis is clinically and radiologically quite different and usually amounts to simple absence of part of the clavicle with no lanceolate deformity (Fig. 5). Again, no case in this series could be regarded as being due to neurofibromatosis with bony defect. Perinatal injury will be discussed later. 


\section{CLINICAL MATERIAI.}

In the series there were twenty-three female and ten male patients. Fifteen patients were first seen between birth and two weeks of age, ten between two weeks and two years, and eight after two years. In the last group, however, the condition had often been noticed years before but medical advice had not been sought. Twenty patients were subjected to operation. In sixteen the lesion was excised and the clavicle was grafted, and in four excision only was done (Table I). The results of operation are summarised in Table II.

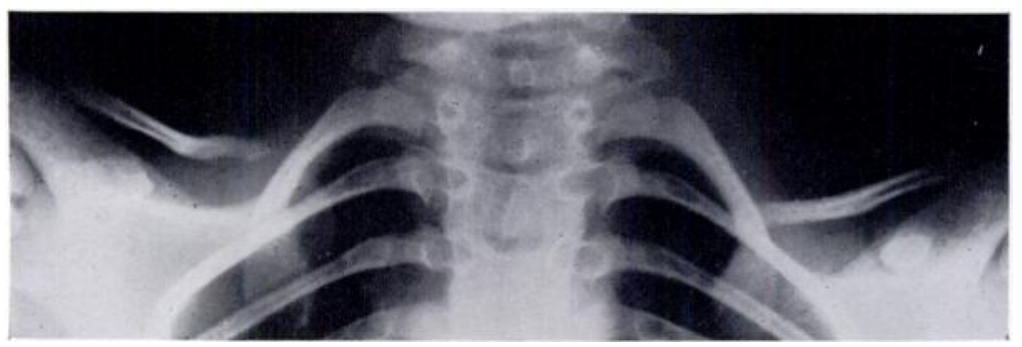

FIG. 5

A case of craniocleidodysostosis with simple aplasia of clavicles contrasting with the marked prominence of pseudarthrosis.

\section{CASE REPORTS}

Case 1 (Mr E. H. Strach's case)-A baby girl was seen at the age of three days with a marked but painless prominence of the right mid-clavicle. There had been no difficulty during delivery. When the girl was four and a half years old the lesion was excised and the defect was bridged

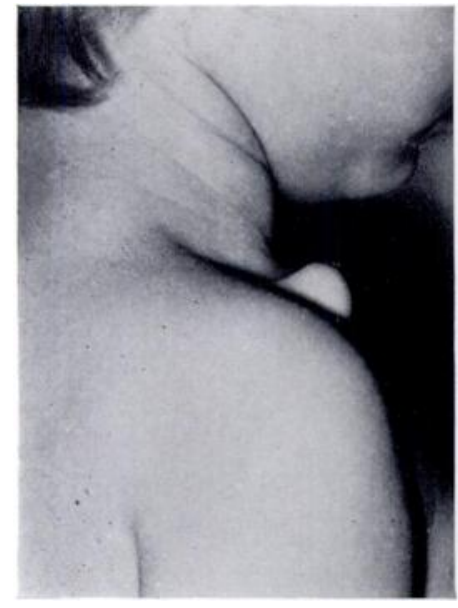

FIG. 6

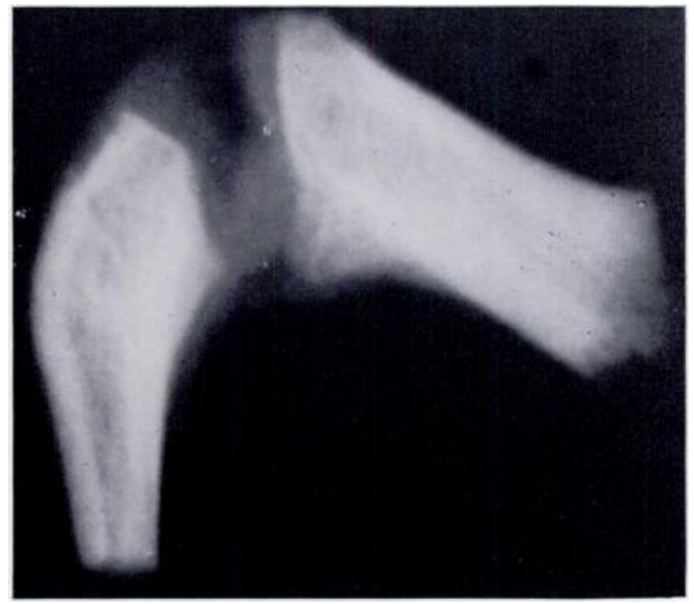

Fig. 7

Case 1-Clinical appearance and radiograph of the excised lesion in a girl of $4 \frac{1}{2}$ years.

with a lozenge of tibia (Figs. 6 and 7). No internal fixation was used, but a plaster spica was applied. Four months after operation the graft was firm and shoulder movements were full.

Case 2 (Mr D. Wainwright's case)—A baby girl was brought at the age of one week with a marked prominence of the middle third of the right clavicle. There was no bruising or tenderness but delivery had been precipitant. Radiographs suggested a congenital anomaly. 
The girl was brought again at the age of nine complaining of increasing deformity (Figs. 8 and 9). Six months later the lesion was excised (Fig. 10). Iliac bone was inserted and Kirschner wire

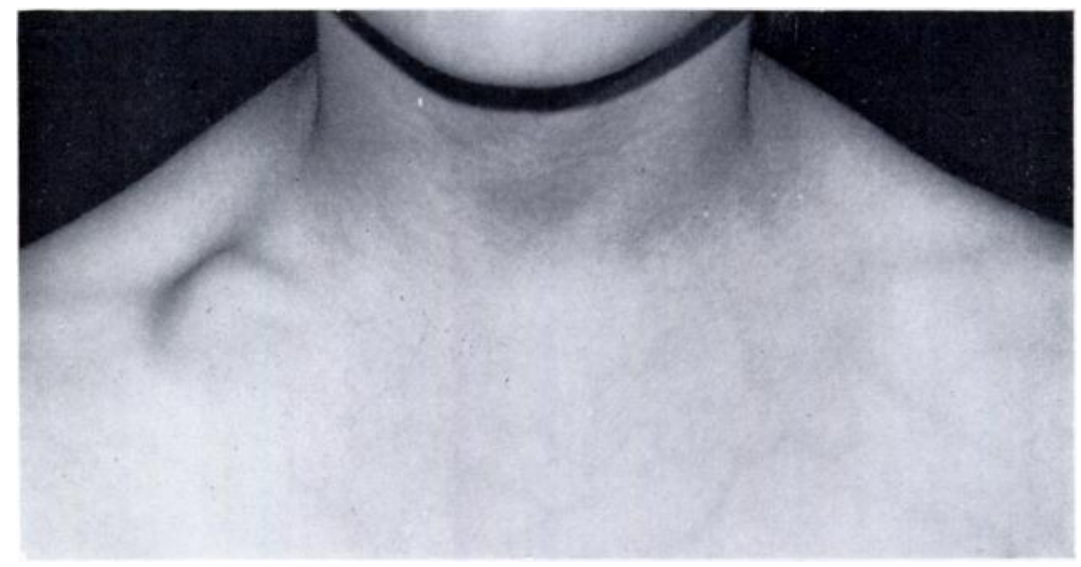

Fig. 8

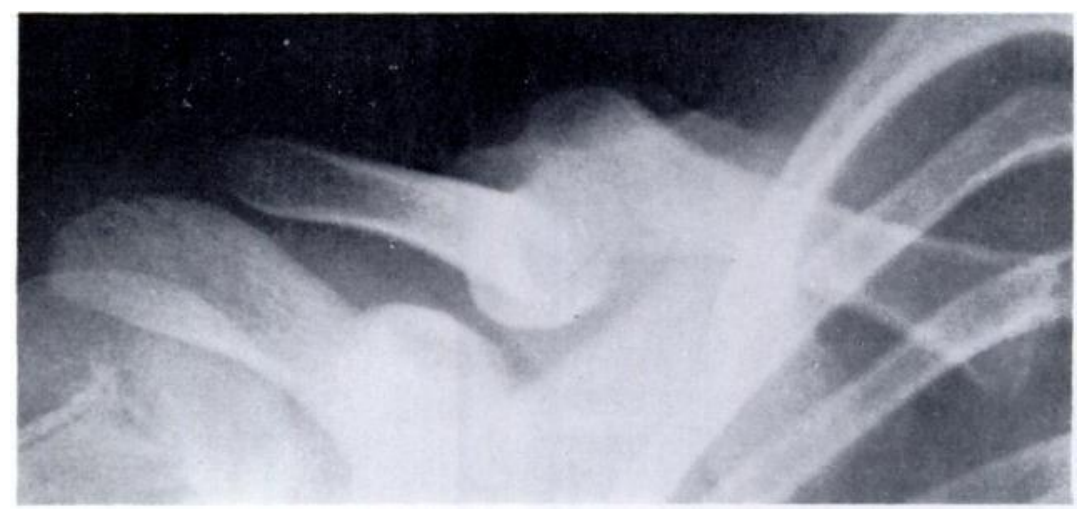

FIG. 9

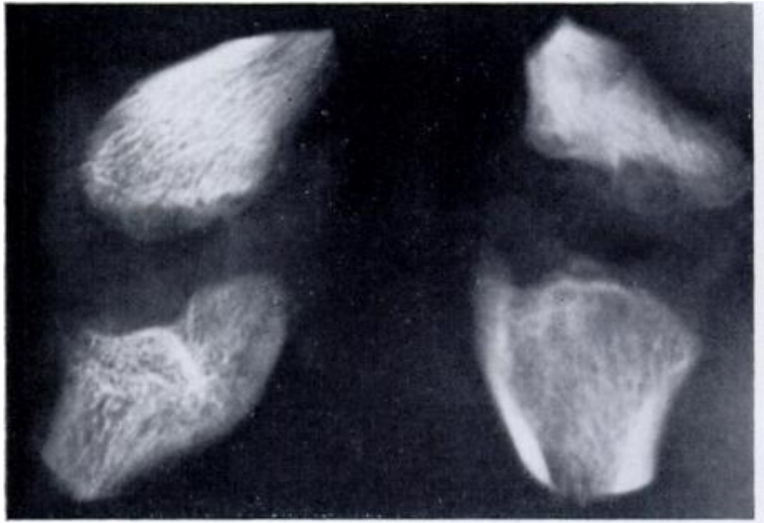

FIG. 10

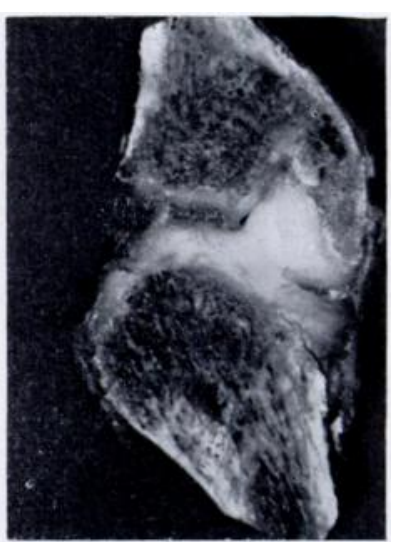

Fig. 11

Case 2-Clinical, radiographic and pathological features. Figures 8 and $9-$ Clinical appearance and radiograph of the affected right clavicle. Figure 10-Macroradiograph of the excised joint. ( $\times 2$.$) Figure 11-Macroscopic appearance of the specimen showing a diarthrodial joint. (\times 2$.

was used for fixation. The specimen showed a true joint space with surrounding fibrous tissue (Fig. 11). 
Case 3-A girl was brought at the age of two and a quarter years with painless deformity of the right clavicle (Fig. 12). The lesion had been found the previous year by the mother. There was no history of birth trauma. General examination was negative and radiographs showed no abnormality in the skull, pelvis or hands. Radiographs of the shoulder showed a defect

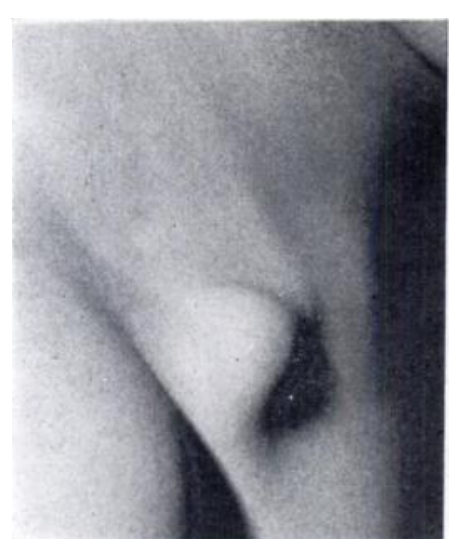

FIG. 12

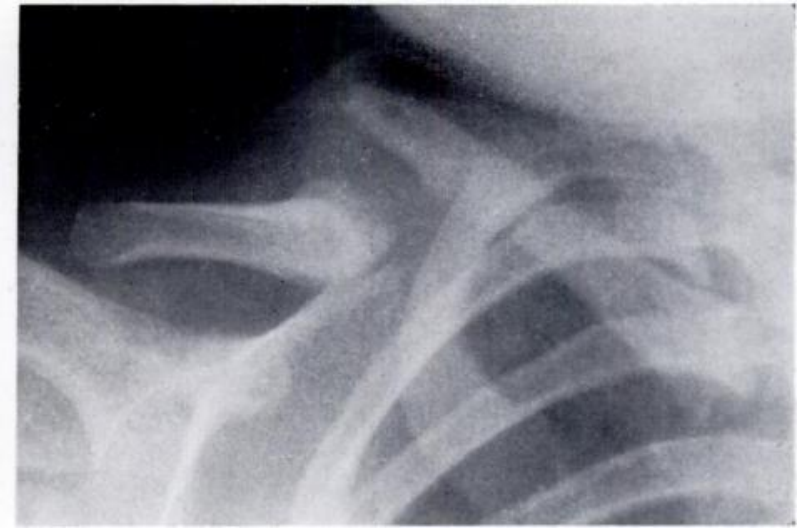

FIG. 13

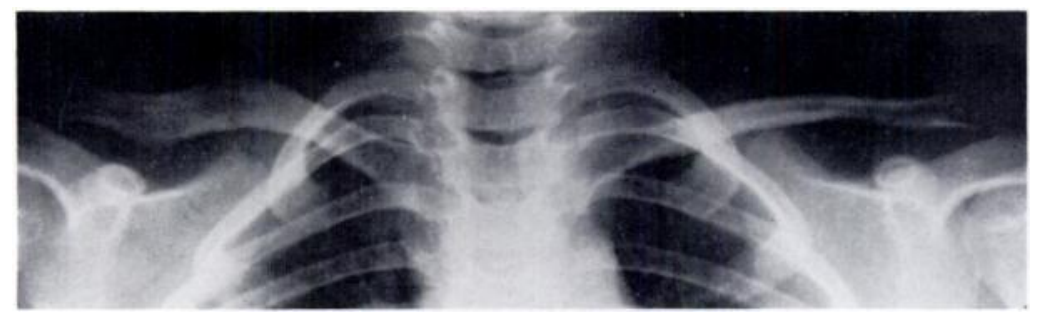

FIG. 14

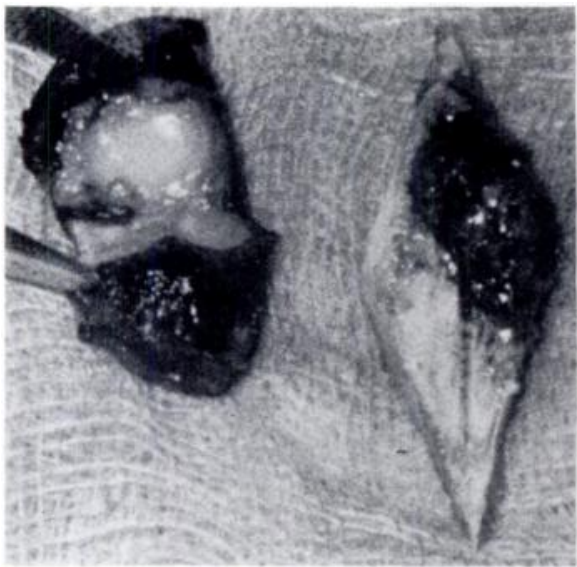

FIG. 15

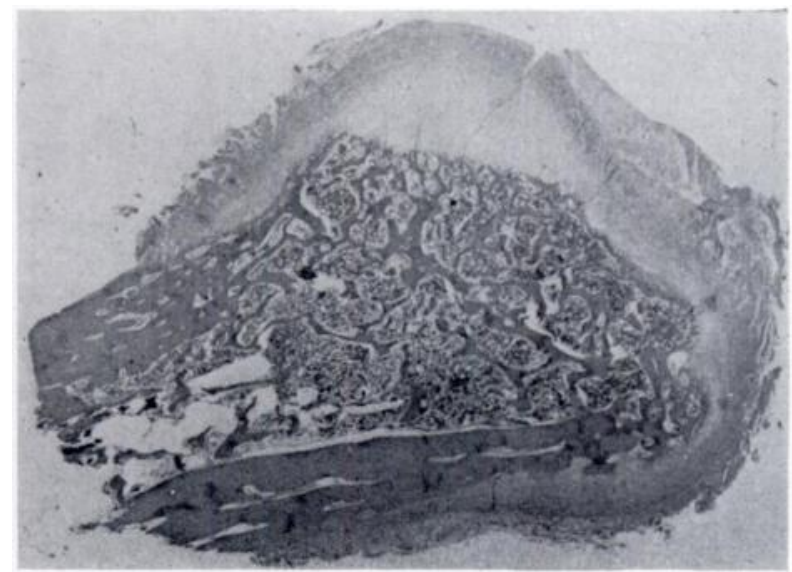

FIG. 16

Case 3-Clinical, radiographic and pathological features. Figure 12-Girl at the age of 3 years. Figure 13Radiograph before operation. Figure 14 - Union and remodelling at one year after grafting. Figure 15The excised joint and the shaped tibial graft. Figure 16-Low-power microphotograph of one segment of the joint.

in and some foreshortening of the clavicle (Fig. 13). The girl was kept under observation until she was nearly four years old; then, because of increasing deformity, operation was advised.

At operation the pseudarthrosis was excised, sclerotic bone being removed until healthy tissue was reached. The two ends were carefully drilled to fashion a channel to receive the 
lozenge-shaped tibial graft. This was sprung into place and cancellous bone was packed around it. No internal fixation was used. The shoulder girdles and arms were firmly immobilised on a plaster crucifix for ten weeks. Three months later union was sound.

A radiograph twelve months after operation showed union with remodelling (Fig. 14). The girl has now been under observation for nine years and function and appearance of the shoulder are good.

Figure 15 shows the graft used and the area of pseudarthrosis opened out showing the false joint lined with basophil hyaline cartilage bordered by ragged pseudo-capsule. The low-power photomicrograph shows details of this (Fig. 16). The hyaline cartilage of the joint surface with the underlying bone is evident. Such a joint was reported in fourteen cases. In three others there was a bridge of irregular collagenous fibrous tissue with areas of cartilage and osteoid merging into the underlying sclerotic bone. In the remaining three cases no histological findings were available.

\section{TECHNIQUE OF OPERATION}

An arcuate skin incision low down over the second rib is used (Fig. 17). This avoids the supraclavicular nerves and any keloid can be hidden by clothing. Furthermore, the skin in this area during the period of rapid growth in childhood migrates upwards into the neck, and unless the scar is situated low down it might become prominent later. If possible, one

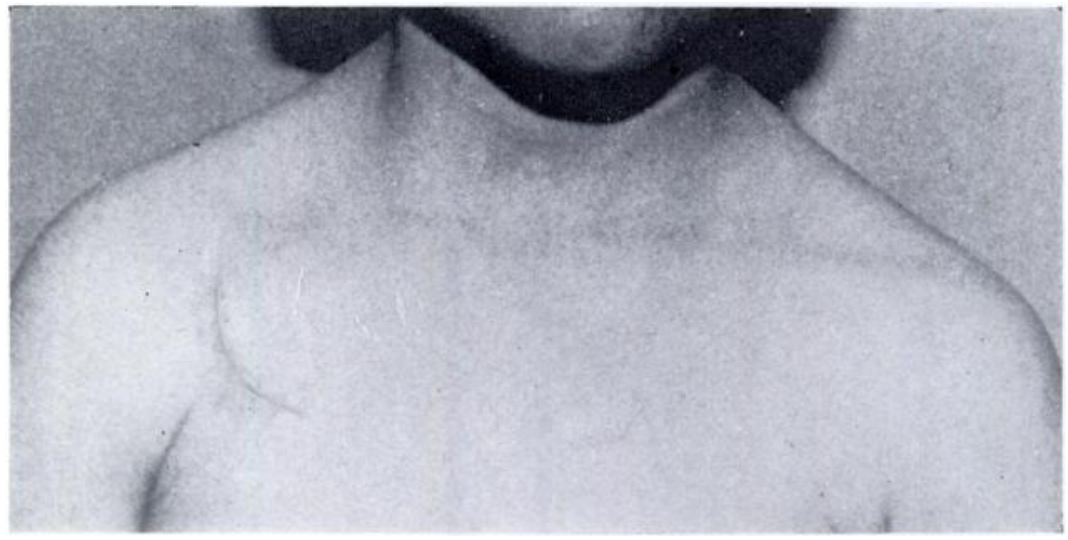

FIG. 17

Arcuate scar overlying second rib.

should avoid metal fixation of any sort as the clavicle seems to be peculiarly intolerant of metal. Removal of metal was necessary in four cases, giving rise to slow union in three and necessitating regrafting in one. Low-grade sepsis occurred in two cases. The graft may be taken from a rib, the iliac crest or the tibia; it must be autogenous. Grafting is advisable in patients up to ten years old; the best age for operation is between three and five years. In the four cases where excision only had been done the patients complained of aching: asymmetry was still present and with certain movements the clavicular stumps were still prominent.

\section{DISCUSSION}

The clavicle is almost certainly of composite origin. Embryologists consider it to be derived partly from a covering of dermal bone and partly from a ventral primary bar (Arey 1934, Frazer 1958, Andersen 1963). These two coalesce early into a composite whole. This is the first osseous mass to form in the embryo and appears in the 11-millimetre stage at the fourth week as a mesenchymal bar lying obliquely below the precoracoid area in the neck. There is still doubt whether it is a pure membrane bone or derived from cartilage. Most are 
agreed, however, that at the fifth week a state of pre-cartilage exists in the mesenchymal bar with two ossific plaques present in its long axis. The seventh week may well be the vital period in development because it is at this stage that the pre-cartilaginous masses with their bony nuclei fuse (O'Rahilly 1967).

Any arrest in the normal processes at this stage could lead to aplasia. With this possibility in mind a study of infants with congenital skeletal defects was carried out. The radiographs of seventy ectromelic babies with severe upper limb defects from three major centres in Britain were reviewed. The clavicles were particularly well formed in all cases, except in one girl who showed possible pseudarthrosis of the right clavicle at birth. The scapulae nearly always were boomerang-shaped, with a long acromion process as one limb and the body of the scapula

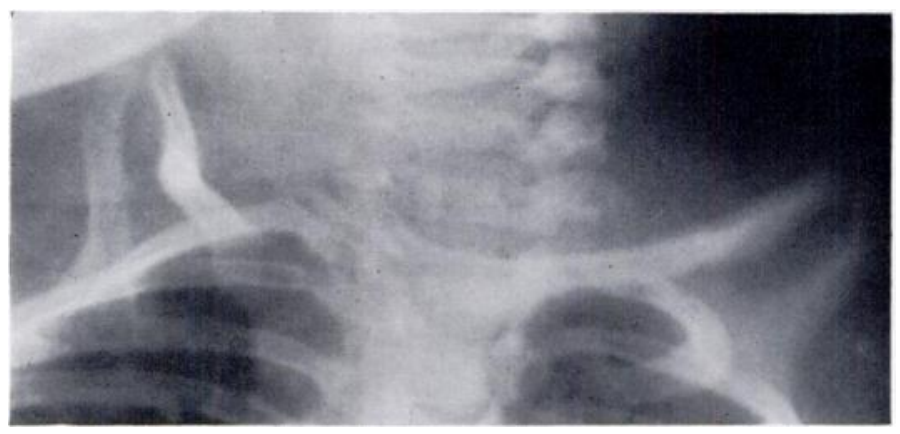

FIG. 18

The boomerang scapulae and well formed clavicles in a thalidomide infant.

as the other (Fig. 18). A possible point of significance in this study is that the clavicle is well developed in the embryo at a time that the limb buds more distally are still vulnerable to noxious factors. Thus if clavicular pseudarthrosis is developmental, the critical phase must exist before the forty-fifth day of development.

Alldred (1963) was firmly of the opinion that clavicular pseudarthrosis was developmental, appearing early in intra-uterine life. Although this may be so in most cases, an element of trauma in the perinatal period, occurring in a clavicle that is already abnormal in structure, is possible. One fact is clear-the defect is not due to non-union of a birth fracture of normal bone. In our experience all neonatal clavicular fractures united readily leaving no disability. In a large obstetric unit twelve birth fractures of the clavicle occurred in a total of 6,893 deliveries. These were all treated personally by the author-all healed rapidly, leaving no trace of deformity.

Of special interest is the fact that all the defects in the series were right sided, as were Alldred's cases and others in the literature. No adequate explanation has yet been offered for this. Bearing in mind that there may be a traumatic background to these cases, either during intra-uterine development or in the natal passages, an approach to gynaecologists and anatomists for a satisfactory explanation proved fruitless. Right-handedness, methods of delivery, or the position of the mother during labour are possible clues. That a high percentage of babies present in the left occipito-anterior position during vertex delivery and that the right shoulder is often caught against the symphysis pubis may possibly be relevant although unlikely.

No convincing genetic pattern has evolved in the series (except in the case of the father and daughter) but it is conceded that an exhaustive investigation of the families was not done except in my personal cases. It must be admitted therefore that one cannot be categorical on the etiology of this curious defect. 
Whether the lesion be developmental or produced by other environmental causes, treatment should be by operation-preferably during the third or fourth year of life. Excision and bone grafting ensure symmetrical shoulder girdles and good function.

\section{SUMMARY}

1. Thirty-three cases of congenital pseudarthrosis of the clavicle are presented.

2. The lesions all occurred in the right clavicle and are thought to be due to abnormal intrauterine development rather than non-union of birth fractures.

3. Methods of treatment are reviewed. Excision and bone grafting is favoured.

I wish to record my sincere thanks to all colleagues listed below for allowing me access to their cases, and for their ready encouragement: Messrs F. G. Allan, J. N. Aston, N. J. Blockey, J. P. Campbell, J. A. Cholmeley, A. C. Clark, R. A. Denham. F. C. Dwyer, A. L. Eyre-Brook, P. C. Fulford, A. M. Hendry, J. P. Jackson, T. E. McSweeney, S. A. S. Malkin, C. W. Manning, J. D. Morgan, R. D. Muckart, K. I. Nissen, R. Roaf, R. H. C. Robins, R. L. Samilson (U.S.A.), J. C. Scott, I. S. Smillie, E. H. Strach, D. Wainwright and J. N. Wilson.

To Mrs M. Stevens (Departmental Superintendent), Mrs J. H. Challis and Mrs V. A. Thomas (Research Secretaries) I am greatly indebted for help in preparing the text, and to Messrs B. Southern, G. Tushingham and H. G. Crabtree for their photographic expertise.

\section{REFERENCES}

Alldred, A. J. (1963): Congenital Pseudarthrosis of the Clavicle. Journal of Bone and Joint Surgery, 45-B, 312. ANDERSEN, H. (1963): Histochemistry and Development of the Human Shoulder and Acromioclavicular Joints with Particular Reference to the Early Development of the Clavicle. Acta Anatomica, 55, 124.

Arey, L. B. (1934): Developmental Anatomy. Third edition, p. 354. Philadelphia: Saunders.

Carpenter, E. B., and Garretr, R. G. (1960): Congenital Pseudarthrosis of the Clavicle. Journal ofBone and Joint Surgery, 42-A, 337.

Cesarani, F. (1947): Pseudo-artrosi della clavicola da pregressa lesione traumatica. Annali di radiologia diagnostica, 19, 160.

Fitzwilliams, D. C. L. (1910): Hereditary Cranio-cleido-dysostosis. Lancet, 2, 1466.

Foco, G. (1946): Pseudo-artrosi clavicolare. Annali di radiologia Diagnostica, 18, 93.

Frazer, J. E. (1958): Anatomy of the Human Skeleton. Second edition, p. 60. London: J. \& A. Churchill Ltd.

Henderson, M. S. (1923): Nonunion in Fractures: the Massive Bone Graft. Journal of the American Medical Association, 81, 463.

Moore, J. R. (1949): Delayed Autogenous Bone Graft in the Treatment of Congenital Pseudarthrosis. Journal of Bone and Joint Surgery, 31-A, 23.

O'Rahilly, R. (1967): In Normal and Abnormal Embryological Development, p. 10. Edited by C. H. Frantz. National Research Council Publication 1497. Washington, D.C.

Pessagno, A. (1954): Sulla pseudoartrosi della clavicola. Radiologia medica, 40, 885.

Saint-Pierre, L. (1930): Pseudarthrose congénitale de la clavicule droite. Annales d'anatomie pathologique et d'anatomie normale médico-chirurgicale, 7, 625.

Sakellarides, H. (1961): Pseudarthrosis of the Clavicle. Journal of Bone and Joint Surgery, 43-A, 130.

Støren, H. (1946): Old Clavicular Pseudarthrosis with Late Appearing Neuralgias and Vasomotoric Disturbances Cured by Operation. Acta Chirurgica Scandinavica, 94, 187. 